\title{
Differences in dental age of small gestational age children based on the severity of enamel dental defects
}

\author{
Annisa Maya Kania*, Roosje Rosita Oewen*, Williyanti Suwondo* \\ Departement of Pedodontics Faculty of Dentistry Universitas Padjadjaran
}

\begin{abstract}
Small Gestational Age (SGA) is the term used for a new born baby with birth-severe below the $10^{\text {th }}$ percentile on the intrauterine Lubchenco curve, due to Intra Uterine Growth Restriction (IUGR) which can cause defects of several organs such as deciduous teeth enamel. Dental age is the indicator for growth and development of the teeth that determine biological age which is more accurate than chronological age and could be determined by calcification or teeth eruption. The purpose of this study was to obtain dental age in SGA children based on the enamel defect severity level of deciduous teeth as compared to the chronological age. This study was a comparative analytic study with given sample size, conducted towards 18 SGA children aged 4-6 years old, and 21 children with Appropriate Gestational Age (AGA) aged 4-6 years old as the control group. Deciduous teeth enamel defect severity level determined by the developmental defect of enamel (DDE) score FDI modified. In order to determine the permanent teeth growth and development, the indicator was based on dental age using the panoramic radiograph with Dermijian method. The t-test was used to compare the permanent teeth dental age difference between SGA and AGA children as well as the permanent teeth dental age difference of SGA children based on the enamel defect severity level of deciduous teeth as seen in their chronological age. The result showed that there was a difference in the permanent teeth dental age between the SGA and AGA children at chronological ages of $4,, 5$, and 6 years old (t count $=3,36 ; 2,35$; and 3,49). Based on the average of permanent teeth dental age, the value of AGA children was higher than SGA children. Furthermore, it also showed that the severe score of EDS in the SGA children at the age of 4, 5, and 6 years old, their permanent teeth dental age was lower than the mild EDS ( $t$ count $=1,45$ ). The conclusion of this study was the permanent teeth dental age in SGA children was lower than the AGA children as well as difference between the permanent teeth dental age in SGA children based on their deciduous teeth enamel defect severity, and the severe defect refered to slower permanent teeth dental age than the mild defect.
\end{abstract}

Keywords : Dental age. deciduous teeth enamel defect, Small Gestational Age (SGA)

\section{INTRODUCTION}

SGA is an infant born with an intrauterine growth delay with severe lying below the $10^{\text {th }}$ percentile in the intrauterine growth chart of Lubchenco. SGA can be born less moon (premature), enough month (matur) or even more month. ${ }^{1}$ SGA occurs due to intrauterine growth retardation (IUGR) which is the growth barrier experienced by infants in the womb caused by maternal, fetal and placental factors. IUGR can affect fetal development and lead to developmental defects of various organs, including defects in the teeth. The development of deciduous teeth, can be disturbed because of the prenatal period is a critical time of formation of teeth, especially deciduous teeth and some permanent dental seeds. ${ }^{2,3}$ The presence of interference in the development of enamel and calcification can lead to the occurrence of a sedentary defect, and result in a network structure abnormalities hard teeth in both primary and permanent teeth. ${ }^{4,5,6,7}$ The defect of enamel is an imperfection of enamel, which occurs when disruptions in the growth and development of enamels. E-mail defects can occur in prenatal, neonatal and postnatal periods. ${ }^{8}$ 
The condition of dental growth and development can be seen from dental age, because dental age is more accurate than chronological age. Determination of dental age is performed based on the stage of calcification or tooth eruption, the most commonly used estimate of maturation. Dermijian uses radiographic images to measure the level of dental maturation. ${ }^{5,9}$

Past research has shown that SGA children experiencing eruption late on primary teeth, while research Williyanti in 2009 showed that 79\% of children SGA risk for experiencing deciduous teeth enamel defects. This study aims to obtain a permanent dental dental age in SGA children based on the severity of enamel dental defects seen by chronological age.

\section{METHODS}

Research subjects were children with a history of SGA who was born in the Dr. Hasan Sadikin Hospital Bandung in 2004-2006 and at the time of the study aged 4-6 years. As a control was a normal child Appropriate Gestational Age who came to Pedodontic Clinic of Faculty of Dentistry Universitas Padjadjaran Dental Hospital in the period of February-March 2010 and willing to follow the research. Examination of deciduous teeth enamel defects in children SGA, may appears as hypoplasia and hypocalcification. Hypoplasia visible clinical features such as pits, grooves, holes, on the enamel surface, while hypocalcification seen clinical picture in the form of tooth looks blurry / not slippery, and opaque. Criteria severity of deciduous teeth enamel defects was measured by a score of DDE according to a modification of FDI as follows: 1 = Normal: enamel slick, white milk; 2 = EHP HypocalificationOpacity: the presence of no opaque white coloring translucent or brown or yellow; 3 = EHP Hypoplasia enamel-pit: Quantitatively there was a defect, visible pits and grooves on some teeth; $4=$ EHP
Hypoplasia enamel-difuse: visible defect, there was a vertical groove which can also be irregular; 5 = EHP Hypoplasia enamel-linear type: horizontal groove; 6 = EHP Hypoplasia enamel-missing enamel: lost most enamels in multiple locations.

Enamel Defect Score (EDS) was counted by multiplying EHP with the number of teeth with defects times ten, then divided with the number of teeth at risk. The severity was determined by the DDE score of the SGA and AGA children to determine mild defects and severe defects. The mild score was $<12$, while the severe score was $\geq 12$. ${ }^{10}$ Determination of dental age was done by examination of panoramic radiography to see the development stage of crown and root of tooth based on Dermijian method" (based on formation stage of radicular proportion: Phase 0 was when the tooth seeds without signs of calcification; Phase $A$ was when the calcification began on occlusal surface; Phase B was when the occlusal surface of the tooth was noticeable; Phase $C$ was when the calcification of the dental crown has been completed and continued with the formation of the dentin deposit; Phase D was when the formation of the crown of the tooth until the cementoenamel junction; Phase E was when the radicular growth was narrower than the crown height; Phase $\mathrm{F}$ was when the radicular length was equal to or greater than the crown height; Phase $G$ was when the radicular growth was complete, but the apical foramen was still open; Phase $\mathrm{H}$ was the closure of the apical foramen.

Each phase of mineralization was given a useful score to measure the maturation of teeth from a scale of $0-100$. Maturity score was the calculation of the child's age calculated from the score of each level of dental maturation. Calculation of dental age on each gender accumulated which then converted with maturity score table, after converted with maturity score table will be known dental age and dental maturation. ${ }^{11}$

Table 1 Dental age in boys ${ }^{11}$

\begin{tabular}{|l|c|c|c|c|c|c|c|c|c|}
\hline \multirow{3}{*}{ Teeth } & \multicolumn{9}{|c|}{ Phase } \\
\cline { 2 - 11 } & $\mathbf{0}$ & A & B & C & D & E & F & G & H \\
\hline 37 & 0.0 & 2.1 & 3.5 & 5.9 & 10.1 & 12.5 & 13.2 & 13.6 & 15.4 \\
\hline 36 & & & & 0.0 & 8.0 & 9.6 & 12.3 & 17.0 & 19.3 \\
\hline 35 & 0.0 & 1.7 & 3.1 & 5.4 & 9.7 & 12.0 & 12.8 & 13.2 & 14.4 \\
\hline 34 & & & 0.0 & 3.5 & 7.0 & 11.0 & 12.3 & 12.7 & 13.5 \\
\hline 33 & & & & 0.0 & 3.5 & 7.9 & 10.0 & 11.0 & 11.9 \\
\hline 32 & & & & & 3.2 & 5.2 & 7.8 & 11.7 & 13.7 \\
\hline 31 & & & & & 0.0 & 1.9 & 4.1 & 8.2 & 11.8 \\
\hline
\end{tabular}


Table 2 Dental age in girls ${ }^{1}$

\begin{tabular}{|c|c|c|c|c|c|c|c|c|c|}
\hline \multirow[t]{2}{*}{ Teeth } & \multicolumn{9}{|c|}{ Phase } \\
\hline & 0 & A & B & C & D & $E$ & $F$ & G & $\mathrm{H}$ \\
\hline 37 & 0.0 & 2.7 & 3.9 & 6.9 & 11.1 & 13.5 & 14.2 & 14.5 & 15.6 \\
\hline 36 & & & & 0.0 & 4.5 & 6.2 & 13.5 & 14.0 & 16.2 \\
\hline 35 & 0.0 & 1.8 & 3.4 & 6.5 & 10.6 & 12.7 & 13.5 & 13.8 & 14.6 \\
\hline 34 & & & 0.0 & 3.7 & 7.5 & 11.8 & 13.1 & 13.4 & 14.1 \\
\hline 33 & & & & 0.0 & 3.2 & 5.6 & 10.3 & 11.6 & 12.4 \\
\hline 32 & & & & 0.0 & 3.2 & 5.6 & 8.0 & 12.2 & 14.2 \\
\hline 31 & & & & & 0.0 & 2.4 & 5.1 & 9.3 & 12.9 \\
\hline
\end{tabular}

Tabel 3 Maturity Score ${ }^{11}$

\begin{tabular}{|c|c|c|c|c|c|c|c|c|c|c|c|}
\hline $\begin{array}{c}\text { Age } \\
(\text { y.o. })\end{array}$ & Male & Female & $\begin{array}{c}\text { Age } \\
(\text { y.o. })\end{array}$ & Male & Female & $\begin{array}{c}\text { Age } \\
\text { (y.o.) } \\
\end{array}$ & Male & Female & $\begin{array}{c}\text { Age } \\
\text { (y.o.) } \\
\end{array}$ & Male & Female \\
\hline 3.0 & 12.4 & 13.7 & 6.0 & 33.6 & 38.0 & 9.0 & 83.6 & 87.2 & 12.0 & 94.0 & 96.3 \\
\hline .1 & 12.9 & 14.4 & .1 & 34.7 & 39.1 & .1 & 84.3 & 87.8 & .1 & 94.2 & 96.4 \\
\hline .2 & 13.5 & 15.1 & .2 & 35.8 & 40.2 & .2 & 85.0 & 88.3 & .2 & 94.4 & 96.5 \\
\hline .3 & 14.0 & 15.8 & .3 & 36.9 & 41.3 & .3 & 85.6 & 88.8 & .3 & 94.5 & 96.6 \\
\hline .4 & 14.5 & 16.6 & .4 & 36.9 & 41.3 & .4 & 86.2 & 89.3 & .4 & 94.6 & 96.7 \\
\hline .5 & 15.0 & 17.3 & .5 & 39.2 & 43.9 & .5 & 86.7 & 89.8 & .5 & 94.8 & 96.8 \\
\hline .6 & 15.6 & 18.0 & .6 & 40.6 & 45.2 & .6 & 87.2 & 90.2 & .6 & 95.0 & 96.9 \\
\hline .7 & 16.2 & 18.8 & .7 & 42.0 & 46.7 & .7 & 87.7 & 90.7 & .7 & 95.1 & 97.0 \\
\hline .8 & 17.0 & 19.5 & .8 & 43.6 & 48.0 & .8 & 88.2 & 91.1 & .8 & 95.2 & 97.1 \\
\hline .9 & 17.6 & 20.3 & .9 & 45.1 & 49.5 & .9 & 88.6 & 91.4 & .9 & 95.4 & 97.2 \\
\hline 4.0 & 18.2 & 21.0 & 7.0 & 46.7 & 51.0 & 10.0 & 89.0 & 91.8 & 13.0 & 95.6 & 97.3 \\
\hline .1 & 18.9 & 21.8 & .1 & 48.3 & 52.9 & .1 & 89.3 & 92.3 & .1 & 95.7 & 97.4 \\
\hline .2 & 19.7 & 22.5 & .2 & 50.0 & 55.5 & .2 & 89.7 & 92.3 & .2 & 95.8 & 97.5 \\
\hline .3 & 20.4 & 23.2 & .3 & 52.0 & 57.8 & .3 & 90.0 & 92.6 & .3 & 95.9 & 97.6 \\
\hline .4 & 21.0 & 24.0 & .4 & 54.3 & 61.0 & .4 & 90.3 & 92.9 & .4 & 96.0 & 97.7 \\
\hline .5 & 21.7 & 24.8 & .5 & 56.8 & 65.0 & .5 & 90.6 & 93.2 & .5 & 96.1 & 97.8 \\
\hline .6 & 22.4 & 25.6 & .6 & 59.6 & 68.0 & .6 & 91.0 & 93.5 & .6 & 96.2 & 98.0 \\
\hline .7 & 23.1 & 26.4 & .7 & 62.5 & 71.8 & .7 & 91.3 & 93.7 & .7 & 96.3 & 98.1 \\
\hline .8 & 23.8 & 27.2 & .8 & 66.0 & 75.0 & .8 & 91.6 & 94.0 & .8 & 96.4 & 98.2 \\
\hline .9 & 24.6 & 28.0 & .9 & 69.0 & 77.0 & .9 & 91.8 & 94.2 & .9 & 96.5 & 98.3 \\
\hline 5.0 & 25.4 & 28.9 & 8.0 & 71.6 & 78.8 & 11.0 & 92.0 & 94.5 & 14.0 & 96.6 & 98.3 \\
\hline .1 & 26.2 & 29.7 & .1 & 73.5 & 80.2 & .1 & 92.2 & 94.7 & .1 & 96.7 & 98.4 \\
\hline .2 & 27.0 & 20.5 & .2 & 75.1 & 81.2 & .2 & 92.5 & 94.9 & .2 & 96.8 & 98.5 \\
\hline .3 & 27.8 & 31.3 & .3 & 76.4 & 82.2 & .3 & 92.7 & 95.1 & .3 & 96.9 & 98.6 \\
\hline .4 & 28.6 & 32.1 & .4 & 77.7 & 83.1 & .4 & 92.9 & 95.3 & .4 & 97.0 & 99.5 \\
\hline .5 & 29.5 & 33.0 & .5 & 79.0 & 84.0 & .5 & 93.1 & 95.4 & .5 & 97.1 & 98.8 \\
\hline .6 & 30.3 & 34.0 & .6 & 80.2 & 84.8 & .6 & 93.3 & 95.6 & .6 & 97.2 & 98.9 \\
\hline .7 & 31.1 & 35.0 & .7 & 81.2 & 85.3 & .7 & 93.5 & 95.8 & .7 & 97.3 & 99.0 \\
\hline .8 & 31.8 & 36.0 & .8 & 82.0 & 86.1 & .8 & 93.7 & 96.0 & .8 & 97.4 & 99.1 \\
\hline .9 & 32.6 & 37.0 & .9 & 82.8 & 86.7 & .9 & 93.9 & 96.2 & .9 & 97.5 & 99.1 \\
\hline 15.0 & 97.6 & 99.2 & 15.4 & 97.9 & 99.5 & 15.8 & 98.2 & 99.8 & & & \\
\hline .1 & 97.7 & 99.3 & .5 & 98.0 & 99.6 & .9 & 98.3 & 99.9 & & & \\
\hline
\end{tabular}




\begin{tabular}{llllllll}
\hline .2 & 99.4 & .6 & 98.1 & 99.6 & & & \\
\hline .3 & 99.5 & .7 & 98.2 & 99.7 & 16.0 & 98.4 & 100 \\
\hline
\end{tabular}

\section{RESULTS}

Subjects of 39 children with age 4-6 years, divided into two groups of children with a history of SGA as many as 18 people and 21 children of vocational school. All subjects were subjected to a panoramic radiographic examination to determine the dental age of the permanent teeth by using the Dermijian method, specifically in children with a history of SGA, an enamel defect was examined on their primary teeth and the first dental defect recording was performed by DDE (developmental defect of enamel) modification score according to FDI. The severity of the subject enamel defect (EDS) is calculated by the formula as follows:

$E D S=(E H P x$ number of teeth with defects $x 10) /$ (number of teeth at risk)

Descriptively, the SGA group with chronological age 4 years, the average age of permanent teeth dental compared to AGA group there was a difference, on average SGA children dental age was 3.6 years, on average AGA child dental age was 4.8 years, which shows that at chronological age 4 years dental age fixed dent in children of SGA is slower 1 year 2 month than child of AGA.

The SGA group with chronological age of 5 years, the average dental age of permanent teeth is 4.6 years, in children of AGA the mean dental age is 5.5 years, which indicates that at chronological age of 5 years dental age permanent teeth in children SGA 9 months is slower than child of AGA.

SGA group with chronological age of 6 years, average dental age of permanent teeth is 5.6 years, in children SMK average dental age is 6.5 years, which shows that at chronological age of 6 years dental age of permanent teeth in children of SGA 9 months is slower than children of AGA.

The statistical test to see differences in dental age of teeth remain in SGA and AGA children using t-test. The result of statistical analysis showed significant difference of dental age permanent between SGA and AGA children in chronological age 4,5 , and 6 years ( $t$ count $=3,36$, Based on the mean value of dental age in permanent teeth in children of AGA is higher when compared with children SGA seen from chronological age Table 4.

The result of dental dental age difference study was based on the severity of the deciduous first tooth enamel defect based on chronological age of SGA child, which were mild category if EDS score $<12$ and severe category if EDS score $\geq 12.10$, as seen in Table 4 .

In the SGA group with chronological age 4 years, the average dental age based on the severity of the permanent teeth deciduous teeth enamel defects, descriptively looks different, which is the average age of permanent teeth dental of mild EDS was 3.7 years; dental age of permanent teeth in severe EDS was 3.4 years, this shows that the chronological age of 4 years, permanent teeth dental age in SGA children with severe EDS IS slower 3 months than per manentteethdentalageinSGAchildrenwithmildEDS.

SGA group with chronological age 5 years had an average age of permanent teeth dental age with mild EDS was 4.7 years; dental age permanent teeth with severe EDS is 4.4 years, it shows that at chronological age of 5 years, dental age of permanent teeth in SGA child with severe EDS is slower 3 months than dental age of permanent teeth in SGA child with mild EDS.

The SGA group with a chronological age of 6 years had an average age of permanent teeth dental age with mild EDS was 5.65 years; age permanent teeth with severe EDS is 5.3 years, this shows that the chronological age of 6 years, permanent teeth dental age in SGA children with severe EDS is slower 3.5 months than permanent teeth dental age in SGA children with mild EDS.

Based on Table 4, statistical tests to see differences in dental age of teeth remain in SGA children based on the severity of decidous teeth enamel defects using the t-test. The result of statistical analysis, in chronological age group 4 years, mean dental age of permanent teeth based on the severity of the deciduous teeth enamel defect has not showed significant test result in statistical test $(\mathrm{t}$-count $=-0.91 ; \mathrm{t}$-table $=2.26$ ), while for chronological age of 5 and 6 years have not been able to do statistical test in relation not yet fulfill requirement of sample size.

In chronological age group of 4-6 years, the statistical analysis showed significant differences in the average dental age of permanent teeth in children SGA based on the severity of primary teeth enamel defects, with severe EDS slower than mild EDS $(\mathrm{t}=1.45 ; \mathrm{t}$ table $=1.34)$.

\section{DISCUSSION}

Generally the condition of SGA children is less good and high risk, both for short-term and longterm health. ${ }^{1}$ The existence of disturbances in the development of teeth can cause a defect that is permanent and disrupt the process 
of mineralization of deciduous teeth and permanent teeth, thus causing disruption of dental development and late eruption process. ${ }^{5,6}$

Enamel defects can occur in the prenatal, neonatal and postnatal periods. Critical periods of growth and development of deciduous tooth occur during prenatal phase of histodifferentiation (910 weeks), morphodifferentiation (11-12 weeks), aposition, calcification (12-16 weeks). Abnormal tooth structure occurring in the final stages of the bell stage ( $<16$ weeks) may lead to developmental disruption of the enamel resulting in hypoplasia, and when disruption occurs at the calcification stage (> 16 weeks) there will be hypocalcification..$^{5,6,7}$

The enamel defect is any form of deviation from the normal appearance of the enamel layer as a result of disturbance of the function of the formation of enamel organs during the growth and development of enamel. ${ }^{4}$ The defect of enamel may arise from mild to severe and may occur in both deciduous and permanent teeth. This is because enamel defects cause changes in enamel structure and weaken the tooth network resulting in further damage. Enamel does not experience remodeling and resorption, meaning that if the enamel is damaged, then the damage is permanent. ${ }^{4,8}$

The extent of the defect depends on the intensity, duration and time of disturbance at the time of amelogenesis. The intensity, timing and duration of developmental discrepancy of the deciduous tooth will determine the severity of the enamel dental defect severity. The longer and the earlier the disturbance occurs, the worse EDS will also affect the growth and development of the next permanent teeth, as some of the dental seeds still have their formation started when the baby is still in the womb that is before the sixteenth week. ${ }^{7}$

The severity of the defect is determined by calculating EDS (Enamel Defect Score) in each child. These categories are, mildly score $<12$ while the severe score $\geq 12$. The incidence of primary teeth enamel defects in children SGA amounted to $86.93 \%$ and the risk of SGA children to experience the deciduous teeth enamel defects by $79 \% .{ }^{10}$

\section{CONCLUSION}

It was concluded that descriptively, there are differences in permanent teeth dental age based on the severity of the deciduous teeth enamel defects, with severe defects indicate permanent teeth dental age is more slowly than the mild ones.

\section{REFERENCES}

1. Fanaroff AA, Klauss MH. Care of the high risk neonate. 14th ed. Philadelphia: W.B. Saunders Co.; 2003. p. 69-83; 110-5.

2. Hay WW, Thureen PJ, Anderson MS. Intrauterine growth restriction. NeoReviews. 2001 Jun 1;2(6):p. 129-38.

3. The American Academy of Pediatric Dentistry [homepage on internet]. Chicago: Lucille. 2009. Small for gestational age. [cited 2009 Apr]; [about 10 screens]. Available from: http://www.aapd.org.

4. FDI Commission on Oral Health, Research and Epidemiology. An epidemiological index of developmental defects of dental enamel (DDE) index. Int Dent J. 1982 Jun;32(2):159-67.

5. Stewart RE. Pediatric dentistry, scientific foundation and clinical practice. St. Louis: Mosby-Elsevier; 1982. p. 11-9, 87-105.

6. Koch G, Poulsen S. Pedodontics: A Clinical Approach. Copenhagen: Blackwell Munksgaard; 1991. p. 259-263.

7. Avery DR, Dean JA, McDonald RE. Dentistry for the child and adolescent. 2nd ed. St. Louis: Mosby-Elsevier; 2000. p. 45-52, 184-214.

8. Mathewson RJ, Primosch RE. Fundamentals of pediatric dentistry. 3rd ed. Chicago: QuintessencePublishingCo.Inc.;1995.p.78-80.

9. Dermijian A. Dentition. In human growth: A Comprehensive Treatise. 2nd ed. Kentucky: Falknerr \& Tanner; 1986.

10. Suwondo W. Skor prediksi tingkat keparahan defek email gigi sulung pada anak dengan kecil masa kehamilan. Pertemuan IImiah Nasional Ilmu Kedokteran Gigi Anak V Ikatan Dokter Gigi Anak Indonesia (IDGAI); 2009; Makassar, Indonesia. Unpad Press.

11. Clark DH. Practical forensic odontology. London: Wright; $1994 . \quad$ p. 22-40 